\title{
Design of non-linear filter in the problem of structural identification of biomedical signals with locally concentrated properties
}

\author{
Anatoly Povoroznyuk, Anna Filatova, Yuri Myrgorod \\ National Technical University «Kharkiv Polytechnic Institute», Kharkiv, Ukraine \\ Email address: \\ ai.povoroznjuk@gmail.com(A. Povoroznyuk), filatova@gmail.com(A. Filatova),yuriy.myrgorod@gmail.com(Y. Myrgorod)
}

\section{To cite this article:}

Anatoly Povoroznyuk, Anna Filatova, Yuri Myrgorod. Design of Non-Linear Filter in the Problem of Structural Identification of Biomedical Signals with Locally Concentrated Properties. International Journal of Circuits, Systems and Signal Processing. Vol. 2, No. 3, 2013, pp. 85-92. doi: 10.11648/j.cssp.20130203.12

\begin{abstract}
In this paper we propose a generalized method of structural identification of biomedical signals with locally concentrated properties using a digital non-linear filter. The experimental verification of the detecting function was performed by using different ways to describe the model of the desired class of structural elements.
\end{abstract}

Keywords: Structural Identification, Biomedical Signal, Locally Concentrated Properties, Digital Non-Linear Filter, Structural Element

\section{Introduction}

Creation of new informational technologies for assessment of the heart state and cardiovascular system in the design of intellectual computer cardiological decision support systems (ICCDSS) is an important scientific and technical problem. When designing ICCDSS the following main stages of biomedical signals processing (BMS) with locally concentrated properties (LCP) [1]:

1) Registration and digitizing the signal receiving an analog signal and conversion to a digital signal;

2) Signal pre-processing digital filtering, signal separation to individual files in case of simultaneous reception of multiple signals on the same channel;

3) signal structural identification (SI) selection (marking) of informative fragments on the signal noise background, called the structural elements (SE), which can be prongs, cavities and other parts of the BMS with LCP;

4) Determination of structural elements amplitude-timing characteristics definition of amplitude and timing parameters and converting them into physical units based of the marks gained after structural identification;

5) Calculation of diagnostic characteristics depending on research type calculating of respective medical diagnostic characteristics taking into account the time and amplitude characteristics of structural elements for one or more simultaneously registered BMS with LCP;
6) Decision rules synthesis implementation of diagnostic rules adopted in clinical practice taking into account diagnostic characteristics;

7) Diagnosis an automatic diagnosis of heart and cardiovascular system diseases.

Covered BMS with LCP are quasi-periodical signal having a complex shape and carrying the information of the object state on small piece of signal observation interval. One of the critical BMS with the LSP processing stages, which is hardly formalized, is the stage of structural identification. Increasing effectiveness of methods for structural identification is an important task in the design of intellectual computer cardiological decision support systems.

The development of efficient methods for structural identification of BMS with LCP for ICCDSS one should consider the useful signal model (USM), the analysis of which is described in [2 5]. According to USM-1 model biomedical signal can be described as a function of time lattice. This is the simplest model, which does not take into account specifics of BMS with LCP. USM-2 model a model for BMS expansion by basis functions. In USM-2, for instance, Fourier series or wavelets can be used. In model of USM-3 biomedical signal is represented as a function defined on piece-period sequence fragments. At each time interval individual approximation function is given, which describes the structural element. Model USM-4 this is a structural-linguistic representation model for BMS period. 
Model USM-5 BMS with LCP contains a plurality of objects in a property dimension. In USM-5 model one takes into account some features of USM-3 (for objects description it uses parameters of a piece-period approximating functions) and USM-4 (BMS considered as a set of objects).

Based on the USM described above epy following transformation methods with BMS with LCP were isolated: contour analysis $[5,6]$, Fourier transformation and wavelet transformation, modified Hough tranformation [7 9, 11]; structural signal conversion based on grammatical parsing [1] transformation into phase dimension [3, 4], conversion to approximating functions adaptive parameter dimension [1].

Purpose of this paper synthesis of the generalized method of biomedical signals with locally concentrated properties structural identification based on different models of useful signal and conversion methods for BMS with LCP.

\section{Synthesis of a Nonlinear Filter for BMS with LCP Structural Identification}

The problem of structural identification of BMS with LCP can be considered as a local digital signal processing with sliding window or aperture, which by definition is a digital filtering [7 9]. In this case, the window size is chosen much smaller than the signal length, and for each position of the window one runs the same type of actions that define so-called response or filter output. Since the actions defining filter response do not change during the signal scanning, and are defined with nonlinear functions, the SI is performed using the stationary nonlinear filter (NF).

The goal of digital filtering of BMS with LCP is SE of a specific type detection, as well as their location on the given signal. The problem of signal detection is well described in radar [10]. Thus based on the signal parameters for the detection problem the appropriate filters are designed, for example, matched filters, the purpose of which is calculation of some indicators. Indicators analysis with threshold rule makes it possible to decide whether the desired signal is in the mixture of input signal and noise. These ideas were the basis for the synthesis of NF to solve the problem of structural identification of BMS with LCP.

Analysis of USM and conversion methods for BMS with LCP allowed identifying a number of similar actions for solving the SI problem, resulting in a scheme of structural identification of BMS with LCP based on the NF (Fig. 1).

The system input has a digital signal $x[t] \quad\left(t=\overline{0 ; T_{s}-1}\right)$, where $T_{s}$ is the length of the incoming signal. Level 1 conversion $F^{(1)}$ is a method of signal transformation $x[t]$ based on the USM, in which we get a set $K=\left\langle x_{0}[t], \vec{p}, f(x[t], \vec{p})\right\rangle$, where $\quad x_{0}[t] \quad\left(t=\overline{0 ; T_{0}-1}\right) \quad$ a reference signal (model for structural elements of a given class); $T_{0} \ll<T_{s}$ the length of the model; $\vec{p}$ parameters conversion vector; $f(x[t], \vec{p}) \quad x[t] \quad\left(t=\overline{0 ; T_{s}-1}\right)$ signal conversion function within NF response synthesis window. The linear dimensions of the NF window $N_{a}$ are defined by the model linear dimensions $x_{0}[t]$ of a specific class of structural elements, i.e. $N_{a}=T_{0}$.

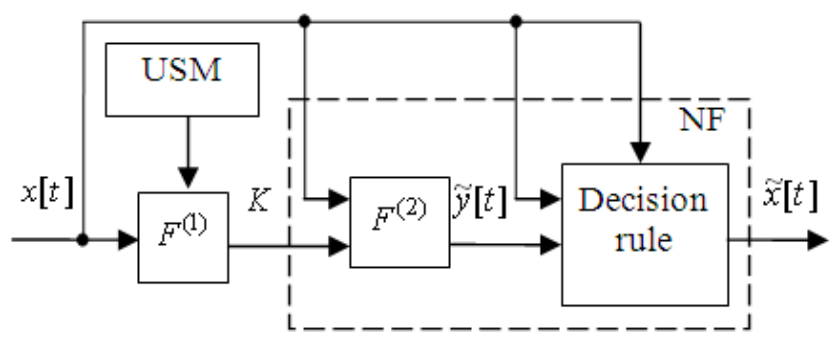

Figure 1. The scheme of structural identification of BMS with LCP based on the NF.

The resulting transfer function $f(x[t], \vec{p})$ is used to describe not only the signal $\omega^{t}$ within the filter aperture, but also to describe the structural elements model $\omega^{m}$ of a specific class, i.e. $y_{j}^{m}=f_{j}\left(x_{0}[t], \vec{p}\right), k=\overline{0 ; T_{0}-1}$, where $y_{j}^{m}, y_{j}^{t}$ the coordinates of the model $\omega^{m}$ and the signal fragment within the window, respectively. Thus, the goal of the 1st level conversion $F^{(1)}$ is to determine the nonlinear filter parameters, such as the linear dimensions of the window and the weight function of the filter, as well as the signal to be detected $x_{0}[t]$.

Level 2 conversions $F^{(2)}$ (see Fig. 1) is getting of a new function in the time dimension $\tilde{y}[t] \in[0 ; 1]$, which indicates the similarity degree between the structural elements model $\omega^{m}$ of desired class and a signal fragment $\omega^{t}$ within the aperture. We call $\tilde{y}[t]$ function detection function, and to use the following function:

$$
\tilde{y}[t]=\frac{1}{1+\alpha \sum_{j=1}^{N_{a}}\left(y_{j}^{m}-y_{j}^{t}\right)^{2}}
$$

where $\alpha \in(0 ; 1]$ coefficient, which reflects the changes sensitivity of structural elements of the same class by applying noise and parameter variations.

Based on the analysis of the detection function $\tilde{y}[t]$ structural identification is performed with help of threshold decision rule:

$$
\tilde{x}[t]= \begin{cases}x[t] \forall t \in\left[t_{0 j} ; t_{0 j}+T_{0}\right], & \text { if } \tilde{y}\left[t_{0 j}\right]>P d ; \\ x^{0} & \text { all other cases }\end{cases}
$$

where $P d$ the threshold value; $t_{0 j}$ the point of local maximum of function $\tilde{y}[t]$, so that $y\left[t_{0 j}\right] \geq \tilde{y}[t]$ $\forall t \in \dot{\mathbf{M}}\left(t_{0 j}\right) ; \quad \dot{\mathbf{M}}\left(t_{0 j}\right)=\mathbf{M}\left(t_{0 j}\right) \backslash\left\{t_{0 j}\right\} \quad$ punctured point neighborhood; $\mathbf{M}\left(t_{0 j}\right)$ point $t_{0 j}$ neighborhood; 
$x^{0}=$ const a constant that determines the level of the signal corresponding to the absence of SE of a given class on the current signal fragment (for example, corresponding isoline contour).

Since the adequacy of a particular USM for each SE is different, in this case for design of a NF we propose to combine local decision rules (LDR) to the collection of decision rules (CDR). As a result, we propose a generalized scheme of structural identification of BMS with LCP based on NF (Fig. 2).

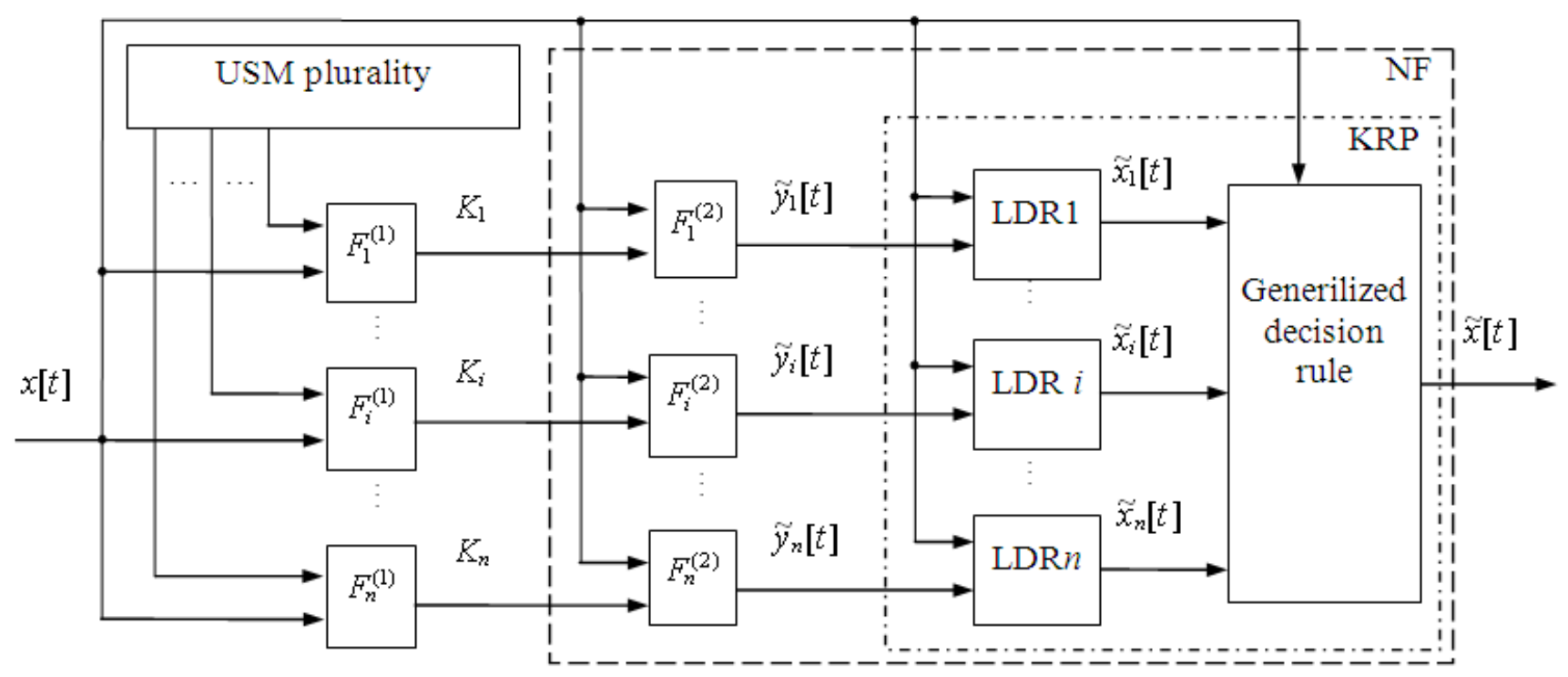

Figure 2. A generalized scheme of structural identification BMS with LCP based on NF.

The scheme shows that the input digital signal $x[t]$ is simultaneously sent to the input of 1 st level $F_{i}^{(1)} \quad(i=1 ; n)$ transformation. Each block output $F_{i}^{(1)}$ generates sets $K_{i}=\left\langle x_{0}[t], \vec{p}_{i}, f_{i}\left(x[t], \vec{p}_{i}\right)\right\rangle$, where $\vec{p}_{i}$ vector parameter of $i$ conversion; $f_{i}\left(x[t], \vec{p}_{i}\right) i$ signal $x[t]\left(t=\overline{0 ; T_{s}-1}\right)$ conversion function within the aperture. In this case, the structural elements model of a given class $x_{0}[t] \quad\left(t=\overline{0 ; T_{0}-1}\right)$ must be the same for all kinds of 2 nd level transformations $F_{i}^{(2)} \quad(i=\overline{1 ; n})$. As a result of each 2 nd level $i$ transformation $F_{i}^{(2)}$, functions $\tilde{y}_{i}[t]$ are calculated using (1). Based on the detection functions $\tilde{y}_{i}[t]$ with the help of local decision rules (LDR) (2) local filter responses $\widetilde{x}_{i}[t]$ are determined, i.e. structural identification is performed. Thus, $i$ local decision rule (LDRi) has the following form:

$$
\tilde{x}_{i}[t]= \begin{cases}x[t] \forall t \in\left[t_{0 i j} ; t_{0 i j}+T_{0}\right], & \text { if } \tilde{y}_{i}\left[t_{0 i j}\right]>P d_{i} \\ x^{0} & \text { all other cases }\end{cases}
$$

where $P d_{i}$ the threshold value of $\operatorname{LDR} i ; t_{0 i j}$ a local maximum point of $\tilde{y}_{i}[t]$ function, so that $\tilde{y}_{i}\left[t_{0 i j}\right] \geq \tilde{y}_{i}[t]$ $\forall t \in \dot{\mathbf{M}}\left(t_{0 i j}\right) ; \dot{\mathbf{M}}\left(t_{0 i j}\right)=\mathbf{M}\left(t_{0 i j}\right) \backslash\left\{t_{0 i j}\right\}$ a punctured neighborhood of $t_{0 i j}$ point; $\mathbf{M}\left(t_{0 i j}\right)$ neighborhood of $t_{0 i j}$ point.

Research of detection functions $\tilde{y}_{i}[t]$ shows that using various USM and transformation methods and of BMS with LCP generally for the $j$ structural element of the desired form $t_{0 i j} \neq t_{0 k j}$ with $j \neq k$. Therefore, the application of generalized decision rule is performed in two stages. The first stage a helper function is evaluated with majority rule $z[t]:$

$$
z[t]= \begin{cases}1, & \forall t \in\left[t_{0 j}^{\prime} ; t_{0 j}^{\prime \prime}+T_{0}\right] \\ 0 & \text { otherwise }\end{cases}
$$

where $t_{0 j}^{\prime}=\min \left(t_{0 i j} \in \mathbf{L}_{j}\right), \quad t_{0 j}^{\prime \prime}=\max \left(t_{0 i j} \in \mathbf{L}_{j}\right)$ the minimum and maximum values of the index of found structural elements $\mathbf{L}_{j}$ in the $j$ signal fragment. The $\mathbf{L}_{j}$ set is formed by the rule $t_{0 i j} \in \mathbf{L}_{j}$, if $\exists t \in\left[t_{0 i j} ; t_{0 i j}+T_{0}\right]$, so that

$$
\frac{1}{n} \sum_{i=1}^{n} z_{i}[t] \geq \frac{n+1}{2 n} ; \quad z_{i}[t]= \begin{cases}1, & \text { if } \tilde{x}_{i}[t]>x^{0} \\ 0, & \text { otherwise }\end{cases}
$$

where $n$ number of LDR.

Function building $(z[t])$ can be described as follows. Let's CDR contain 3 LDR, i.e. $n=3$. Then, in case of the $j$ structural element detection functions $z_{i}[t]$ superposition is shown in Fig. 3. $\mathbf{L}_{j}=\left\{t_{01 j}, t_{02 j}, t_{03 j}\right\}, t_{0 j}^{\prime}=t_{02 j}$ and $t_{0 j}^{\prime \prime}=t_{03 j}$.

In the second step of getting $z[t]$ function nonlinear filter response is calculated according to the following rule:

$$
\begin{gathered}
\tilde{x}[t]= \begin{cases}x[t] \forall t \in\left[\bar{t}_{0 j} ; \bar{t}_{0 j}+T_{0}\right], & \text { if } \mathrm{z}\left[\bar{t}_{0 j}\right]=1 ; \\
x^{0} & \text { if } \mathrm{z}\left[\bar{t}_{0 j}\right]=0 ;\end{cases} \\
\bar{t}_{0 j}=\sum_{i \in \mathbf{L}_{j}} w_{i} t_{0 i j},
\end{gathered}
$$

where $\bar{t}_{0 j}$ average position of the $j$ structural element of a 
given type; $\mathbf{L}_{j}$ the index set of LDR for the $j$ structural element; $w_{i}$ the weights, taking into account the contribution of each LDR to CDR.

In the simplest case

$$
w_{i}=\frac{1}{\left|\mathbf{L}_{j}\right|},
$$
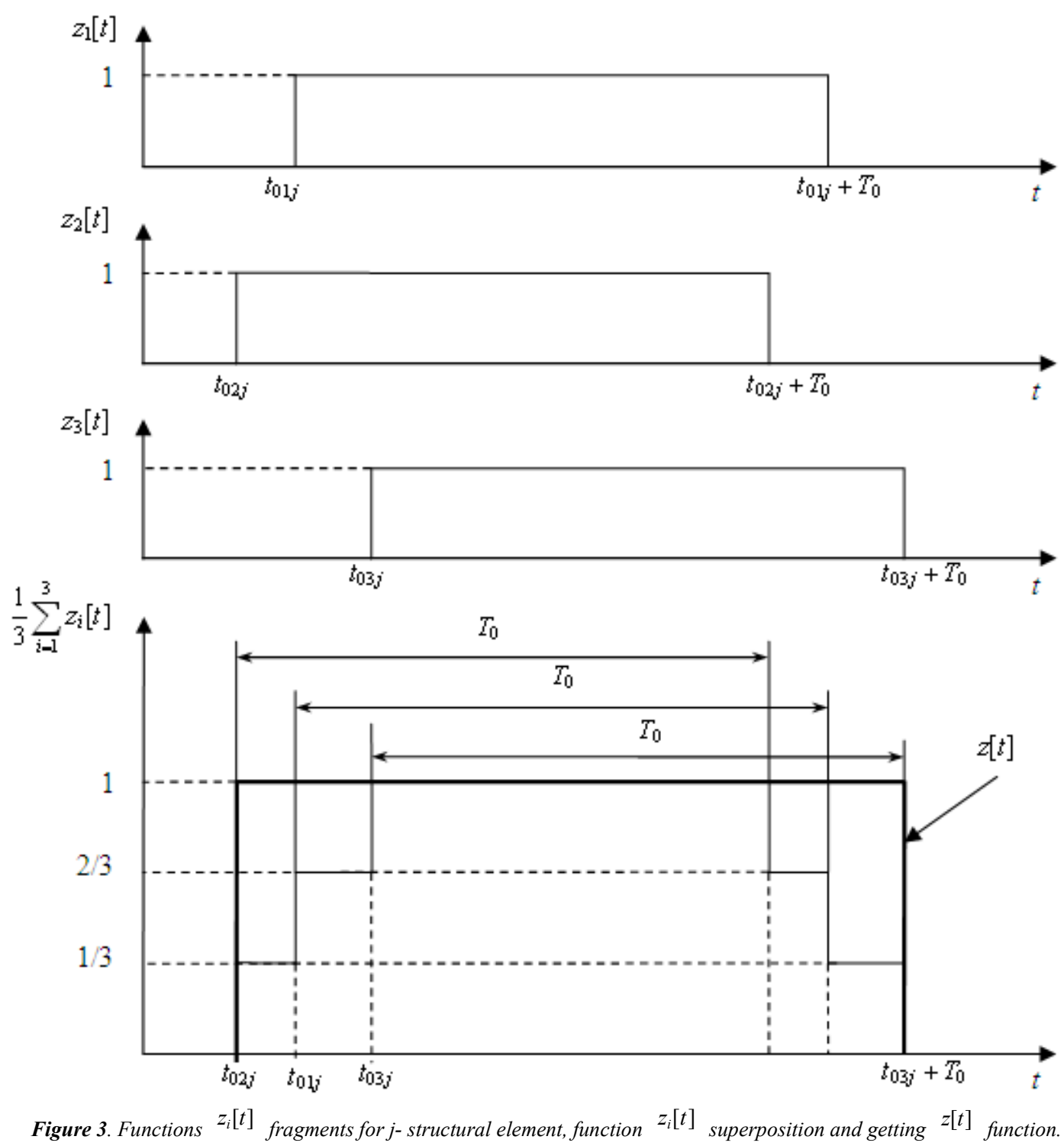

\section{Experimental Verification of the Detection Function Calculation with Different Ways to Set the Model}

As noted above, the result of $F_{i}^{(1)}$ transformation is the $K_{i}=\left\langle x_{0}[t], \vec{p}_{i}, f_{i}\left(x[t], \vec{p}_{i}\right)\right\rangle$ set. Thus the transformation function $f_{i}\left(x[t], \vec{p}_{i}\right)$ is not only used to describe the $\omega_{i}^{t}$ signal within the filter aperture, but also to describe the $\omega_{i}^{m}$ model of structural elements given class, i.e. $y_{i j}^{m}=f_{i j}\left(x_{0}[t], \vec{p}_{i}\right), y_{i j}^{t}=f_{i j}\left(x[t], \vec{p}_{i}\right)$, where $y_{i j}^{m}, y_{i j}^{t}$ the where $\left|\mathbf{L}_{j}\right|$ the cardinality of the $\mathbf{L}_{j}$ set.

Thus, the filter response is determined by the kind of transformation $F_{i}^{(2)}$ and of CDR. In its turn, type of $\tilde{y}_{i}[t]$ function after $F_{i}^{(2)}$ conversion directly depends on the structural elements model description $x_{0}[t]$ of the desired class. 
described with $\vec{a}$ vector, and the function describing the model transition from the time dimension to defining with $\vec{a}$ coefficient vector is the required $f_{i}\left(x[t], \vec{p}_{i}\right)$ function in the $K_{i}$ set. Then the $\omega_{i}^{m}$ model description based on USM-2 is the following: $y_{i j}^{m}=a_{k}$ for $j=\overline{1, N_{i}}$ and $k \in \mathbf{S}_{k}$, where $N_{i}=\left|\mathbf{S}_{k}\right|$ the number of coordinates used to describe the model; $\mathbf{S}_{k} \subseteq\left\{0,1, \ldots, T_{0}-1\right\}$ the set of coefficient indexes $a_{k}$, required to describe the model. In this case the $\vec{p}_{i}$ characteristics vector contains $T_{0}$ and $\mathbf{S}_{k}$. If all the coefficients $a_{k}\left(k=0 ; T_{0}-1\right)$ are used to describe the model, then $\mathbf{S}_{k}=\left\{0,1, \ldots, T_{0}-1\right\}$ and $N_{i}=T_{0}$.

Let's consider the result examples for building detection

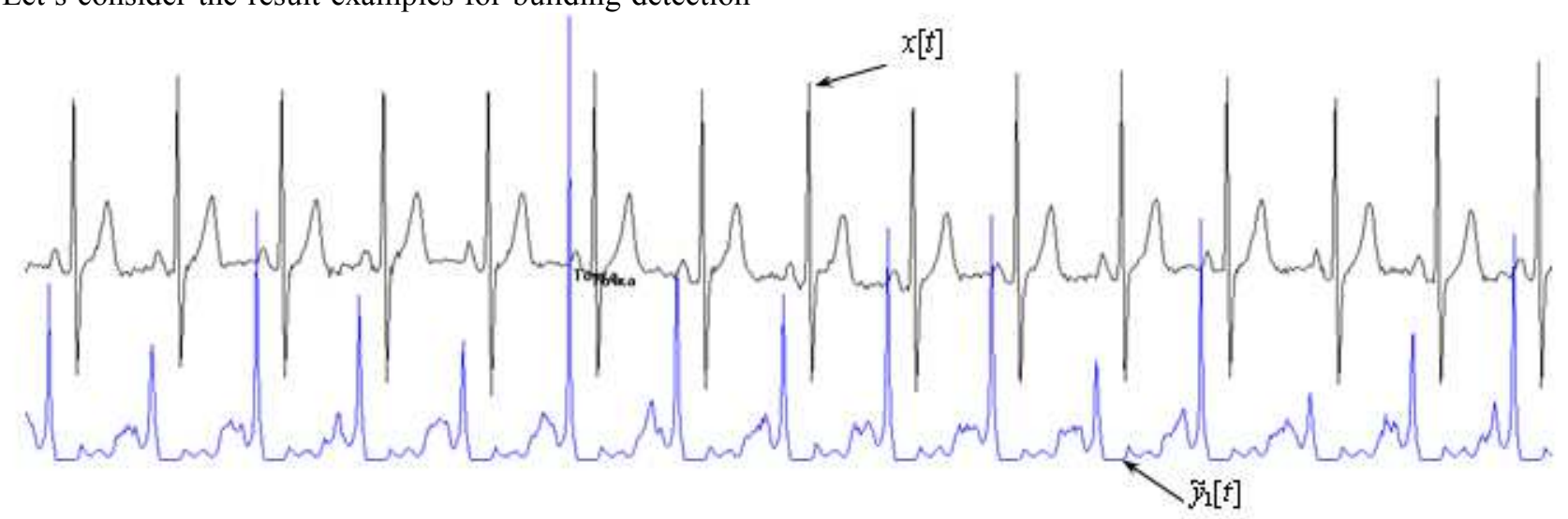

(a)

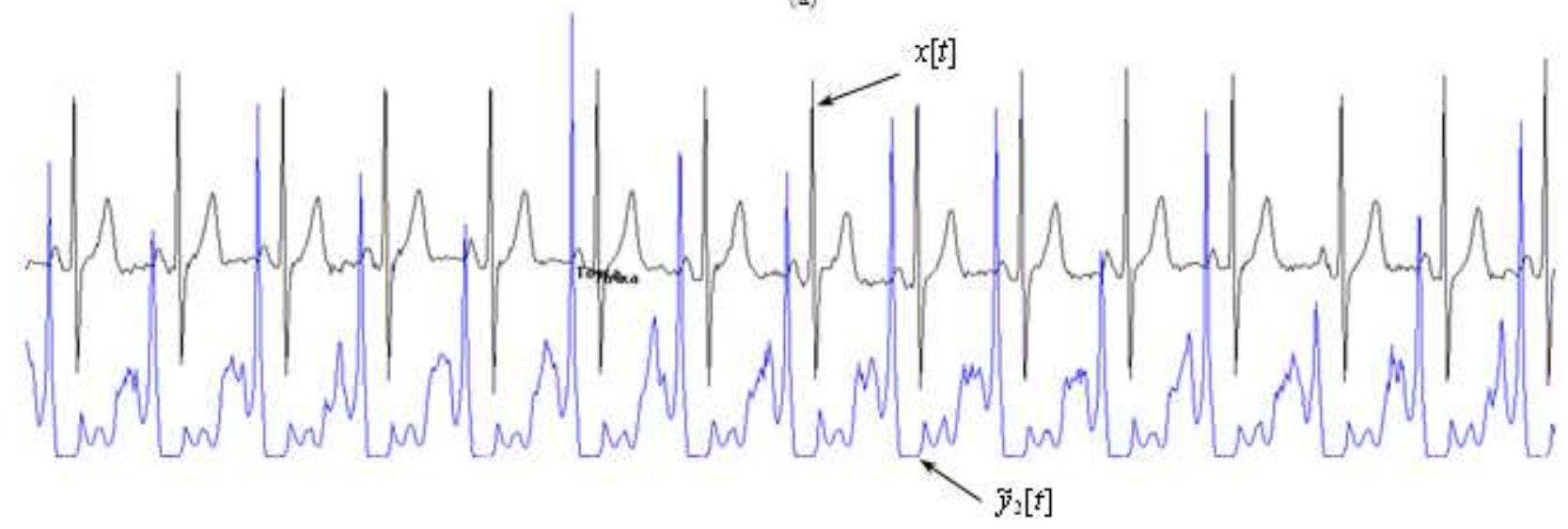

(b)

Figure 4. Graphs of the source signal ${ }^{x[t]}$ (V4 ECG channel) and detection function $\tilde{y}_{i}[t]$ : (a) $\alpha=0,15$; (b) $\alpha=0,05$.

The model signal $x_{0}[t]$ based on USM-5 can be described using a variety of support functions (SF) suggested in [1]. For SF one can use divided differences, the coefficients of the approximating polynomials and other functions. It should be noted that unlike USM-2 inverse does not exist. In this case $x_{0}[t]$ is divided into sections with reference points, and each model fragment can be described with corresponding SF (Fig. 5). function $\tilde{y}_{i}[t]$ after $F_{i}^{(2)}$ conversion at different $\alpha$ values using Haar wavelets to obtain the $a_{k}$ coefficients (Fig. 4).

Fig. 4 clearly shows that the $\tilde{y}_{i}[t]$ function has local maximums at the fragments corresponding to the start points of the structural elements of the specified type (in this case the ECG P-wave). On the fragment corresponding to the beginning of the model (in Fig. 4 it is highlighted with points) function $\tilde{y}_{i}[t]=1$. Also with decreasing the $\alpha$ parameter the local maximums become more prominent, however there are other local maximums in areas that do not correspond to the structural elements of a given type. 
of reference points in the filter aperture. Let's consider results examples for building the function $\tilde{y}_{i}[t]$ after $F_{i}^{(2)}$ conversion using different SF.

Using 1st level divided difference as SF the model description is the following:

$$
y_{i j}^{m}=\left(x_{0}\left[t_{k+1}\right]-x_{0}\left[t_{k}\right]\right) /\left(t_{k+1}-t_{k}\right), j, k=1,2,
$$

where $t_{k}$ indexes of reference points.

After $F_{i}^{(2)}$ transformation with $\alpha=0,5, \tilde{y}_{3}[t]$ function is obtained shown in Fig. 6(a). Fig. 6(a) shows that "false" peaks may appear which have the form of impulse noise. This is due to the fact that the $\omega^{m}$ and $\omega^{t}$ coordinates calculation using the SF, not all the points that fall under the filter aperture are involved in the calculation (only the reference points are used). Therefore, to remove the impulse noise from the resulting function $\tilde{y}_{3}[t]$ one can use median filter with an aperture of 3 points (Fig. 6(b)).

If we use 1 st and 2 nd level divided differences as SF, the model description is the following:

$$
\begin{gathered}
y_{i j}^{\mathrm{m}}=\left(x_{0}\left[t_{k+1}\right]-x_{0}\left[t_{k}\right]\right) /\left(t_{k+1}-t_{k}\right), j, k=1,2, \\
y_{i 3}^{\mathrm{m}}=\left(y_{i 2}^{\mathrm{m}}-y_{i 1}^{\mathrm{m}}\right) / T_{0},
\end{gathered}
$$

where $t_{k}$ indexes of reference points. As a result of $F_{i}^{(2)}$ transformation with $\alpha=0,5$ we get $\tilde{y}_{4}[t]$ function (Fig. 7(a)) and filtered function $\tilde{y}_{4}[t]$ after median filtering with an aperture of 3 points (Fig. $7(\mathrm{~b})$ ).

Fig. 7(a) shows that adding a 2nd level divided difference into the nonlinear filter aperture did not get rid of the impulse noise, so it is advised to use the median filtering for $\tilde{y}_{4}[t]$ function.

The main advantage of using 1 st and 2 nd level divided differences as support functions is the small computing complexity. We then get good enough functions $\tilde{y}_{i}[t]$ which can be used to perform SI with local decision rules (3).

As SF we can use a derivative of the 1st level approximating function, i.e. among the reference points we can describe the model with the following functions:

$$
x_{j}[t]=a_{0 j}+a_{1 j} t+\varepsilon_{j}[t], t \in\left[t_{k} ; t_{k+1}\right]
$$

where $j$ number of the fragment among the reference points; $t_{k}$ the indexes of reference points; $a_{0 j}, a_{1 j}$ the coefficients of the approximating function; $\varepsilon_{j}[t]$ approximation error.

Then the description of the model is: $y_{i j}^{m}=a_{1 j}, j=1,2$. The $F_{i}^{(2)}$ with $\alpha=0,5$ transformation results is the function $\tilde{y}_{5}[t]$ (Fig. 8).

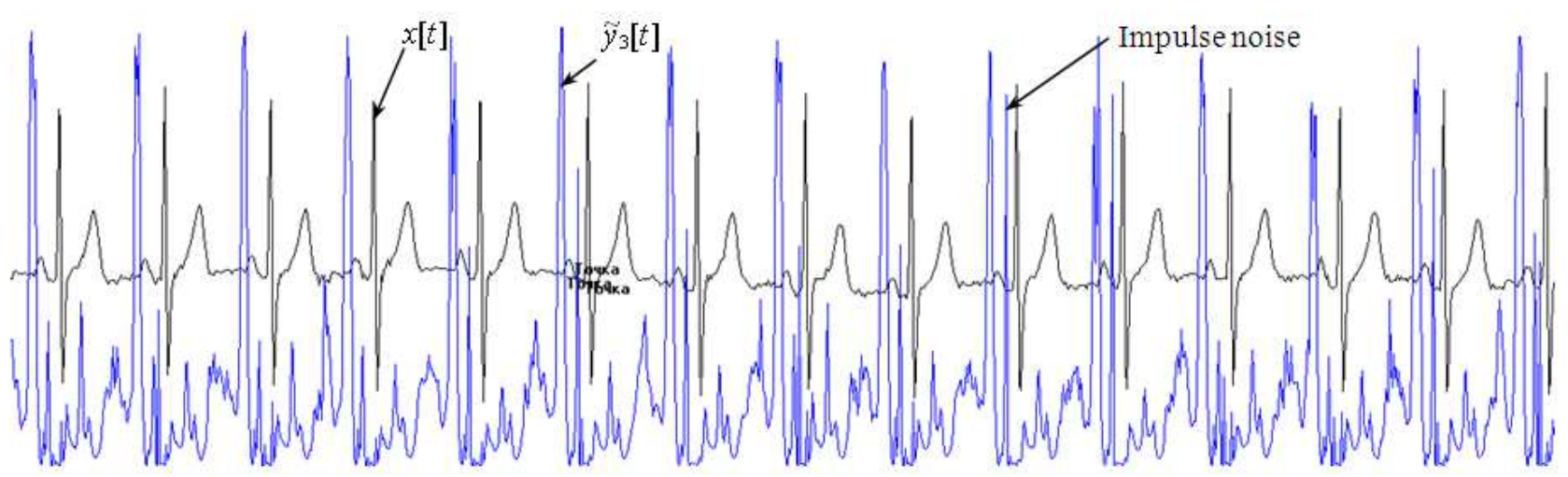

(a)

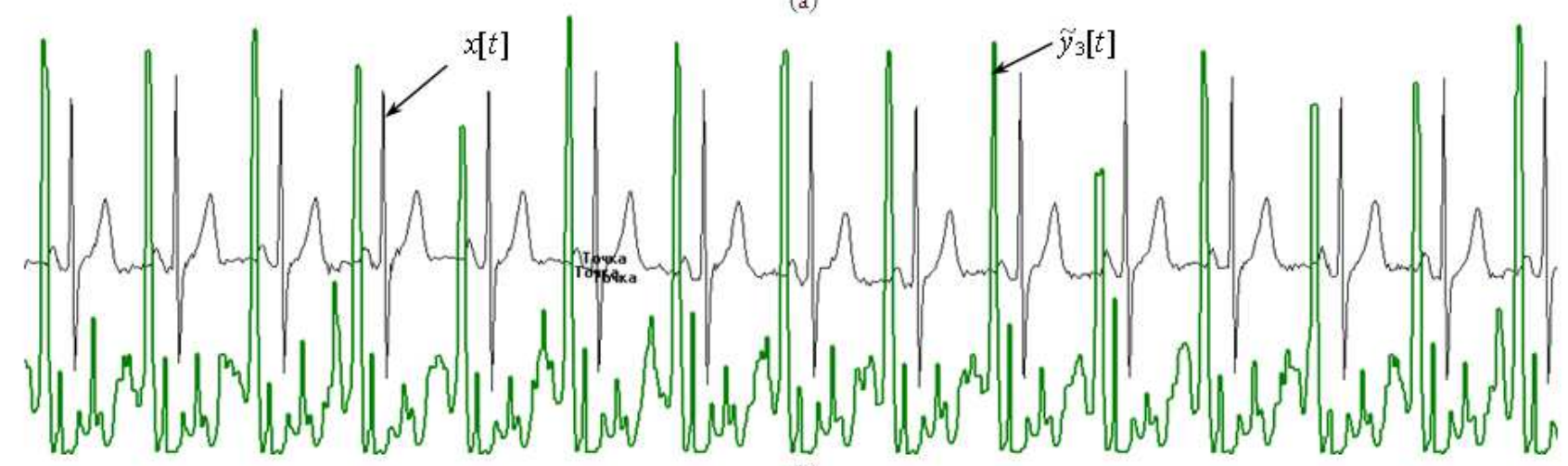

(b)

Figure 6. Graphics of the original signal ${ }^{x[t]}$ (ECG channel V4) and detection function $\tilde{y}_{3}[t]$ : (a) original function $\tilde{y}_{3}[t]$; (b) filtered function $\tilde{y}_{3}[t]$ 


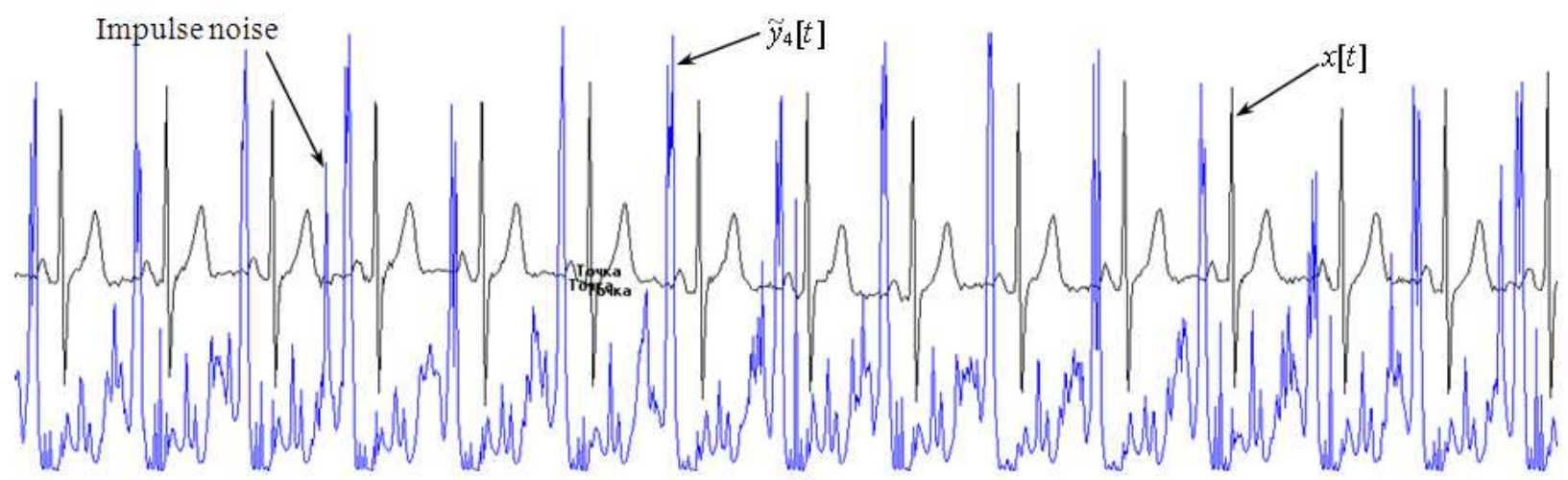

(a)

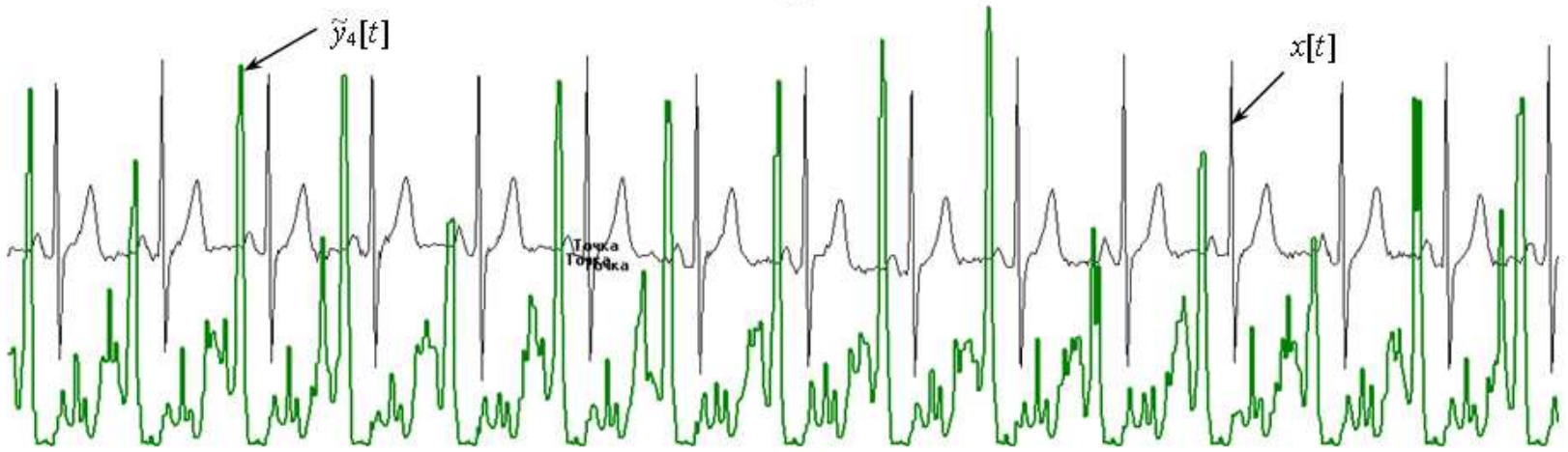

(b)

Figure 7. Graphics of the original signal $x[t]$ (ECG V4 channel) and detection function $\tilde{y}_{4}[t]:$ (a) the original function $\tilde{y}_{4}[t]$; b) filtered function $\tilde{y}_{4}[t]$.

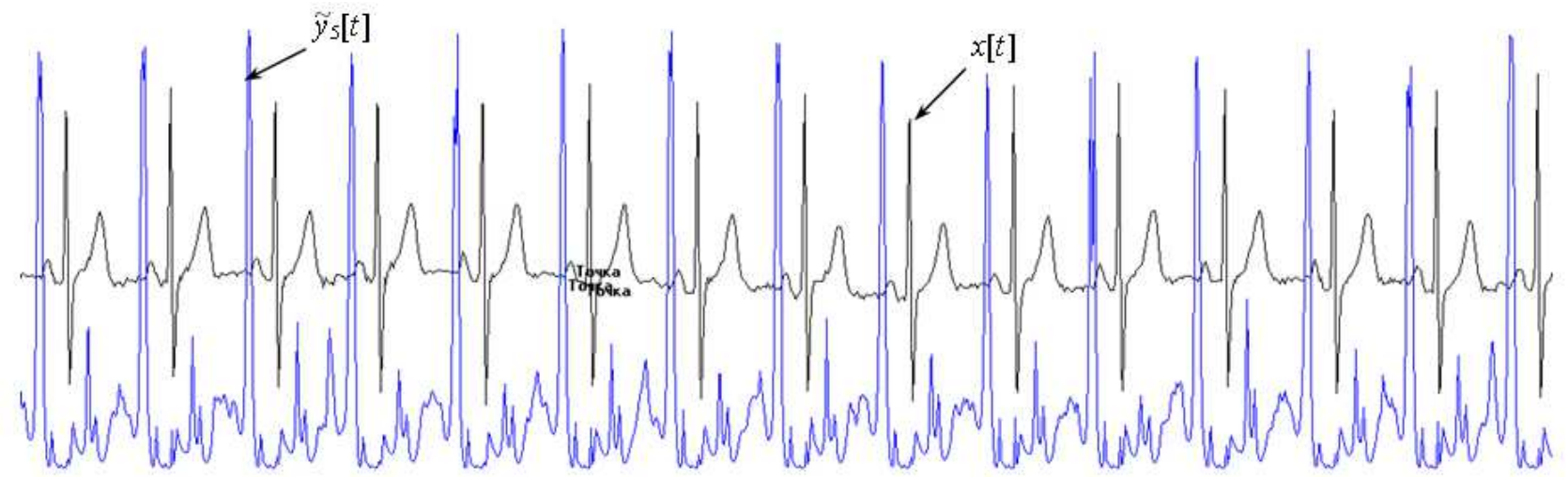

Figure 8. Graphics of the original signal ${ }^{x[t]}$ (ECG V4 channel) and detection function $\tilde{y}_{5}[t]$.

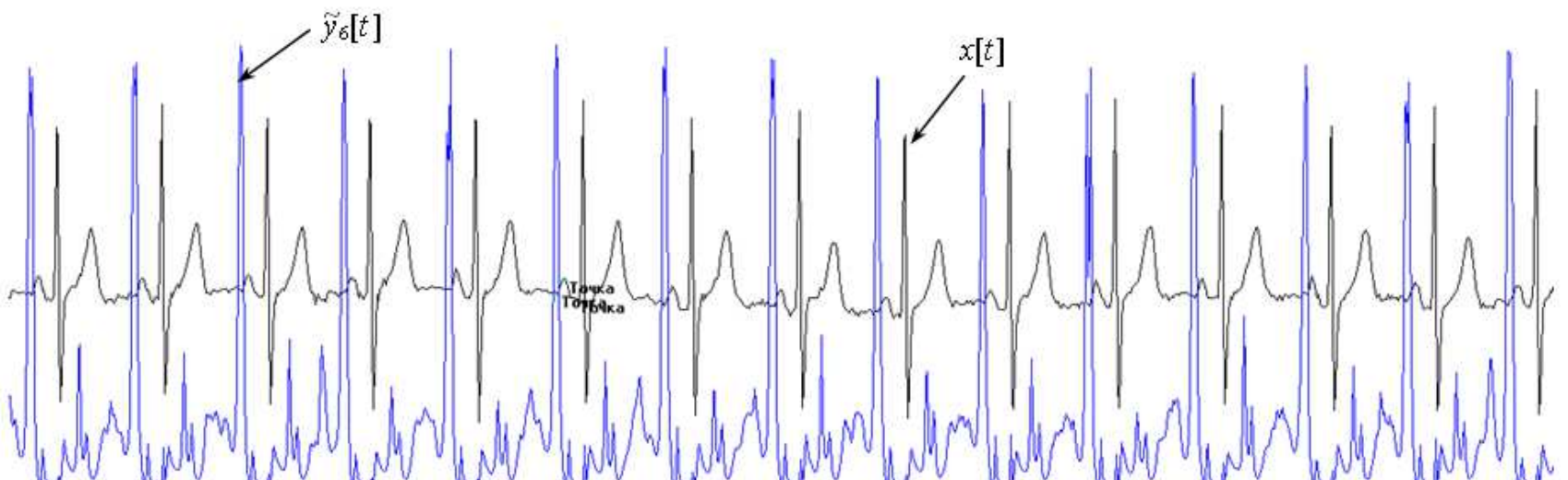

Figure 9. Graphics of the original signal ${ }^{x[t]}$ (ECG V4 channel) and detection function $\tilde{y}_{6}[t]$. 
Since for some kind of structural elements the adoption of the linear dependency among the points is a rather rough approximation, it is better to use a 2 nd level approximating function derivative as the SF, i.e. among the reference points one can use the following functions to define the model

$$
x_{j}[t]=a_{0 j}+a_{1 j} t+a_{2 j} t^{2} \varepsilon_{j}[t], t \in\left[t_{k} ; t_{k+1}\right],
$$

where $j$ fragment number among the reference points; $t_{k}$ the indexes of reference points; $a_{0 j}, a_{1 j}, a_{2 j}$ coefficients of the approximating function; $\varepsilon_{j}[t]$ approximation error.

Then the model description is:

$$
y_{i j}^{m}=x_{j}^{\prime}\left[t_{j}\right]=a_{1 j}+2 a_{2 j} t_{j}, \quad j=1,2
$$

where $t_{j}=\left(t_{k}+t_{k+1}\right) / 2$. The $F_{i}^{(2)}$ transformation result with $\alpha=0,5$ we get the detection function $\tilde{y}_{6}[t]$ (Fig. 9)

Results analysis of the experimental verification for detection function calculation using various USMs showed their acceptable performance level. However, even for the same type of structural elements in different fragments of the signal one can not explicitly pick one of the USMs.

\section{Conclusion}

In this paper we propose a generalized method of structural identification of biomedical signals with locally concentrated properties based on digital non-linear filter. Ways to describe the structural elements model of a specific class using various USMs are discussed. Experimental verification for detection function calculation $\tilde{y}_{i}[t]$ is performed. Further research is focused on experimental verification of the synthesized decision rules set effectiveness using real signals.

\section{References}

[1] Г.Є. Філатова, “Структурна ідентифікація сигналів у кардіологічних системах: дис. канд. техн. наук: 05.11.17”, Харків, 2002, 177 с.

[2] Г.Є. Філатова, “Нелинейная фильтрация биомедицинских сигналов с локально сосредоточенными признаками в задаче структурной идентификации”, Вісник НТУ «ХПІ». Тематичний випуск: Інформатика і моделювання, Харків: НТУ «ХПІ», 2011, № 17, С. 168-174.

[3] A. Povoroznyuk and A. Filatova, "Generalized method of nonlinear filtering of biomedical signals with locally concentrated signs", Material to X international conferences dedicated to the 60th anniversary of the radio department at the Lviv polytechnic national university "Modern problems of radio engineering, telecommunications and computer science proceedings", Lviv-Slavske, 2012, p. 203.

[4] Л.С. Файнзільберг, "Методи та інструментальні засоби оцінювання стану об'єктів за сигналами 3 локально зосередженими ознаками: автореф. дис. на здобуття наук. ступеня доктора техн. наук: спец. 05.13.06”, К., 2004, $35 \mathrm{c}$.

[5] Л.С. Файнзильберг, “ФАЗАГРАФ® эффективная информационная технология обработки ЭКГ в задаче скрининга ишемической болезни сердца", Клиническая информатика и телемедицина, 2010, Т. 6, Вып. 7, С. 22-30.

[6] В.Г. Абакумов, О.І. Рибін, Й.Сватош, "Біомедичні сигнали. Генезис, обробка, моніторинг”, навчальний посібник, К.: Нора-прінт, 2001, 516 с.

[7] "Вычислительные системы и автоматическая диагностика заболеваний сердца”, под ред. Ц. Касереса, Л. Дрейфуса, М.: Мир, 1974, 504 с.

[8] Э. Айфичер, Б. Джервис, “Цифровая обработка сигналов: Практический поход”, М.: Издательский дом «Вильямс», 2004, 992 c.

[9] А.Б. Сергиенко, “Цифровая обработка сигналов: Учебное пособие”, СПб.: Питер, 2006, 752 с.

[10] А.Оппенгейм, Р. Шафер, “Цифровая обработка сигналов”, М.: «Техносфера», 2007, $856 \mathrm{c}$.

[11] Б.Г. Татарский, П.И. Дудник, А.Р.Ильчук, "Многофункциональные радиолокационные системы. Учебное пособие для вузов”, М.: Дрофа, 2007, 283 с.

[12] Ю.В. Миргород, А.И. Поворознюк, “Оптимизация метода идентификации биосигналов на основе преобразования Хока", Вісник НТУ «ХПІ», Збірник наукових праць, Тематичний випуск: Інформатика i моделювання, Харків: НТУ «ХПІ», 2009, № 13, с. 128-132. 